\title{
International Partnerships in Developing and Deploying Health Open Educational Resources
}

\section{Authors}

Airong Luo

Office of Enabling Technologies, University of Michigan Medical School

Enabling Technologies University of Michigan Medical School 4101 Medical Science I 1301 Catherine Street SPC 5624 Ann Arbor, MI 48109-5624

Email: airong|@umich.edu

Garin Fons

Office of Enabling Technologies, University of Michigan Medical School

Enabling Technologies University of Michigan Medical School 4101 Medical Science I 1301

Catherine Street SPC 5624 Ann Arbor, MI 48109-5624

Email: garin@umich.edu

Dick Ng'ambi

University of Cape Town, South Africa

Centre for Educational Technology, the University of Cape Town, Private Bag, Rondebosch, 7701, Cape Town, South Africa

Email: dick.ngambi@uct.ac.za

Gregory Doyle

University of Cape Town, South Africa

Centre for Educational Technology, the University of Cape Town, Private Bag, Rondebosch, 7701, Cape Town, South Africa

Email: gregory.doyle@uct.ac.za

Ana Cleveland

University of North Texas, USA

University of North Texas Department of Library and Information Sciences 1155 Union Circle \#311068 Denton, TX 76203-5017

Email: ana.cleveland@unt.edu 
Lack of training opportunities for new and practicing health care professionals constitutes a major barrier to patient care in many developing countries. Open Educational Resources (OER) hold the potential to provide more training materials and alternative learning opportunities for health professionals. OER are teaching and learning materials made freely and openly available for students, faculty, and self learners around the world. OER is not an online distance learning program. The focus of OER is on scaling up teaching and learning capacity in partner institutions by co-creating new learning materials and converting existing materials into OER.

The context for which OER content is produced is often different from the contexts in which it is used. Thus, one of the major challenges of OER is to understand how to create a sustainable OER model to ensure that OER production and use fit different learning and teaching environments. The panel will share their perspectives on the following issues:

- How are different types of OER created and packaged for delivery and use? - What are the challenges brought about by different contexts of knowledge creation and use?

- How do we design new tools and leverage the existing tools (Sakai course management system, Adobe Connect and similar web conferencing systems, OpenCast and lecture capture systems) to facilitate the creation and use of knowledge?

- How can we produce sustainable models of OER creation and use?

\section{Creating a Sustainable Co-collaboration Model of OER}

In 2008, the University of Michigan (U-M) launched the Health Open Education Resources (OER) initiative, an ambitious project to make comprehensive health curricula available globally via the Internet. A focus of U-M's Health OER effort is to address the education of healthcare providers in developing countries in Africa and anywhere there is a workforce crisis that negatively affects human health. The U-M Medical School is leading this project and working with all U-M health science schools, the School of Information, and five partners in Africa: the University of Cape Town (South Africa), the University of the Western Cape (South Africa), the University of Ghana, Kwame Nkrumah University of Science and Technology (Ghana), and OER Africa. This panel presentation will give a brief introduction to U-M Health OER, and discuss the vision and challenges to create a sustainable model to facilitate faculty's and students' contribution to OER. The panel discussion will cover issues regarding the enhancement of an innovative, low-cost, and scalable process for converting educational materials into OER, and the promotion of collaborative development of educational materials 
as OER. In particular, this panel presentation will introduce dScribe, a University of Michigan initiative in which students help convert curriculum materials into Open Educational Resources (OER).

\section{Challenges of OER in Africa}

Sub-Saharan Africa's infant mortality stands at 103 out of every 1000, compared to developed countries' average of 8 per 1000. $72 \%$ of all people infected with HIV/AIDS reside in Africa. $\mathbf{8 0 \%}$ of infectious diseases are found in Sub-Saharan Africa (SSA).

One of the greatest needs in Africa, therefore, is African-based training using culturally appropriate and high-quality education material to produce qualified health professionals who will be able to deal with Africa-specific health problems.

How would one go about doing this? Where would one find such educational materials? Open Educational Resources (OER) have been hailed as one possibility, but it is also clear that the context within which the OER movement will operate in Africa is substantially different from that of its developed world counterparts.

Africa is often seen as a consumer of materials produced by western countries. However, materials developed by educators or researchers from western countries do not necessarily have immediate insights into the context and challenges of educational delivery in Africa. Challenges faced by health education in Africa include having to train a greater number of students, finding ways to recover costs from students, limited infrastructure (e.g. ICTS and power supply), time allowances for additional work, training and institutional mechanisms to incorporate OER derived programs.

As such how do you get Africa involved in the OER process so that Africans are the drivers/coordinators of projects, not just involved in implementation? How does one increase African practitioners' capacity to produce high quality programs and materials? If they would like to use materials produced elsewhere, how do they develop the expertise and where do they find the funding to adapt it for local use?

The OER movement addresses the aforementioned challenges from two approaches: potentially Africans can become producers of OER; together with educators and researchers in developed countries, they can develop a collaborative development model of OER across universities both in Africa and developed countries. The latter is especially important within a 
context where one of the major costs of African educational systems is that of acquiring pedagogically sound learning materials. Often the resources available to invest in curriculum development or reform - be they financial or human - are simply not available.

Ultimately the goal of the OER movement in Africa should be engaging and supporting African faculty. They are on the ground and have the best knowledge of their own needs, their students' needs, and the constraints and strengths of the circumstances within which they seek to produce a better equipped future generation of Africa's health practitioners.

\section{Creation and Use of OER in Multiple Contexts}

Proponents of Open Educational Resources (OER) have tended to walk a thin-line between content production for a single context on one hand, and content consumption by pluralist audiences in various environments on another hand. We argue that content produced in pluralist environments is much richer and therefore appropriately suitable for use in both single and other pluralistic contexts. However, creating content in pluralistic environments, though invaluable, is challenging. This panel will discuss the single context production environment of OER, for use on both single and multiple contexts; and explore production of OER in pluralistic contexts for use both in single and multiple environments. The panel will address the following questions:

- What underlying assumptions shape the production of OER for single context use?

- How much is understood about pluralist learning environments?

- How does the difference in institutional, cultural and infrastructure between OER production site and use site affect perceptions of OER?

- How does pedagogy affect contents (e.g. didactic contents vs. problem based, tacit, and which requires more collaborative learning).and vice versa?

\section{Organize, Disseminate and Use Medical Information in Latin}

\section{America}

Implementing OER requires a strong understanding of the opportunities and challenges to transfer medical information to medical professionals and information professionals in other countries. Considering experiences in training information and medical professionals to organize, disseminate and use medical information is valuable as we develop methods and 
best practices for OER. This presentation will discuss training, education and research of medical information professionals/medical librarians in Latin America. 